\title{
INVESTIGATION OF UNCERTAINTY FROM CREEP AND CREEP RECOVERY OF FORCE CALIBRATION RESULT IN ACCORDANCE WITH ISO 376:2011
}

\author{
KITTIPONG CHAEMTHET ${ }^{*}$, CHANCHAI AMORNSAKUN, NOPPADON SUMYONG and \\ TAWAT CHANGPAN \\ Mechanical Metrology Department, National Institute of Metrology (Thailand) \\ Pathum Thani, 12120, Thailand \\ kkittipong@nimt.or.th \\ SUMET HEAMAWATANACHAI \\ Department of Mechanical Engineering, Naresuan University \\ Phitsanulok 65000, Thailand \\ sumeth@nu.ac.th \\ sumet@nimt.or.th
}

\begin{abstract}
This paper presents an investigation of the uncertainties from creep and creep recovery of force proving instruments calibrated at NIMT in year 2012 and 2013. In this study, the NIMT's 100kN deadweight force standard machine was used as a standard to calibrate force proving instruments (from various manufacturers and models) in accordance with ISO 376:2011. The comparison of creep uncertainties calculated from creep measured at maximum load $\left(\mathrm{C}_{\max }\right)$, creep recovery measured at zero load $\left(\mathrm{C}_{\text {zero }}\right)$ and reversibility errors were also investigated.

The results of this study show that, for most of the calibration results $(>60 \%)$, the maximum value between $\mathrm{WC}_{\max } / \mathrm{WC}_{\mathrm{zero}}$ and $\mathrm{WC}_{\mathrm{zero}} / \mathrm{WC}_{\max }$ were larger than 2 . Indicating that, $\mathrm{WC}_{\max }$ and $\mathrm{WC}_{\text {zero }}$ could not assume to be equal. For the comparison between creep uncertainties calculated from creep error and reversibility error, more than $80 \%$ of the calibration results, the creep uncertainties calculated from reversibility were larger than 3 time of the calculated values form creep measurement. These gave conclusion that, for the unknown history of creep and reversibility characteristic of instruments, it is more appropriate to estimate the uncertainty of creep from reversibility error.
\end{abstract}

Keywords: Force measurement; calibration; DWM; ISO 376; creep.

\section{Introduction}

In 2011, ISO released a new version of standard for calibration of force proving instrument (ISO 376:2011) ${ }^{[1]}$. This version allows calibrations in 4 cases; A) for specific forces and incremental-only loading, B) for specific forces and incremental/decremental

This is an Open Access article published by World Scientific Publishing Company. It is distributed under the terms of the Creative Commons Attribution 3.0 (CC-BY) License. Further distribution of this work is permitted, provided the original work is properly cited. 
loading, C) for interpolation and incremental-only loading, D) for interpolation and incremental/decremental loading.

Comparing with the previous version (ISO 376:2004) ${ }^{[2]}$, creep property is the additional factor for classification of the force proving instrument. Fig.1a presents the calibration procedure using at the National Institute of Metrology Thailand (NIMT) for calibration of force proving instrument in accordance with ISO 376:2011 ${ }^{[1]}$. Fig.1b shows the details of measurement for evaluation of creep and creep recovery.

As seen in Fig. 1, creep measurement starts after finishing the X'6 series. The $i_{m 30}$ and $i_{m 300}$ are recorded at the 30s and 300s after applying maximum force (these will be used to calculate creep error $-\mathrm{C}_{\max }-$ ). The $i_{z 30}$ and $i_{z 300}$ are record at the $30 \mathrm{~s}$ and $300 \mathrm{~s}$ after reducing force to the zero (these will be used to calculate creep recovery error $-\mathrm{C}_{\text {zero }}-$ ).

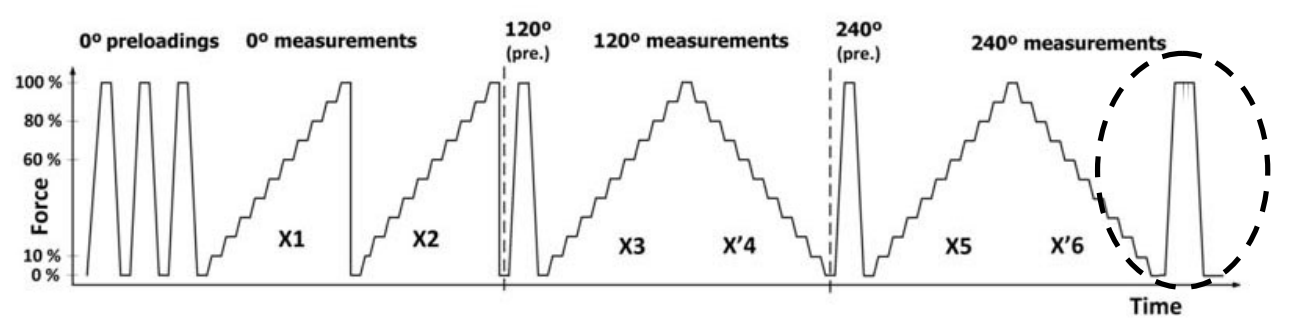

(a) Calibration procedure according to ISO 376:2011 at NIMT.

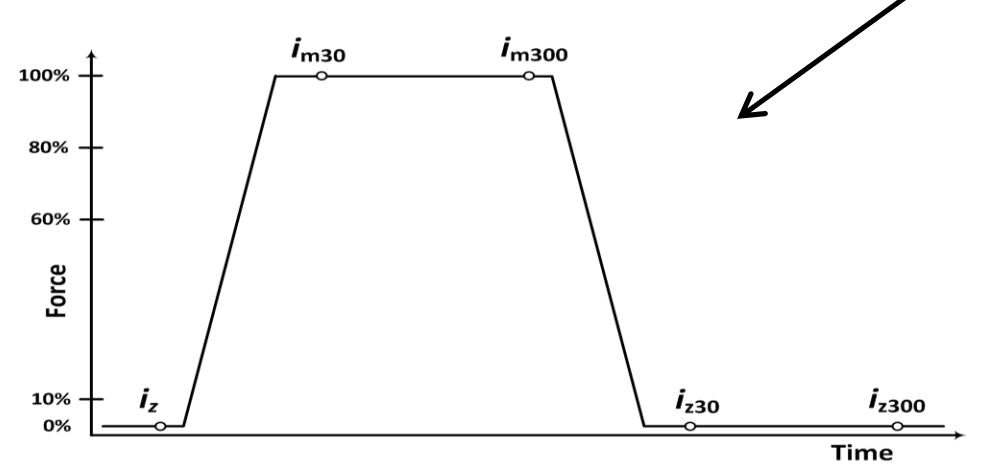

(b) Zoom view of the measurement of creep and creep recovery.

Fig.1 Pattern of calibration according to ISO 376:2011.

\subsection{Equations}

According to the ISO $376: 2011^{[1]}$, the relative creep error $(c)$ can be calculated by using Eq. (1).

$$
c=\left|\frac{i_{300}-i_{30}}{X_{N}}\right| \times 100
$$


where

$$
\begin{aligned}
c= & \text { is the relative creep error in unit } \% \\
i_{300}= & \text { is the reading value of the indicator } 300 \mathrm{sec} \text {. after applied or } \\
& \text { removed of the maximum calibration force }\left(i_{m 300}, i_{z 300}\right) \\
i_{30}= & \text { is the reading value of the indicator } 30 \mathrm{sec} \text {. after applied or } \\
& \text { removed of the maximum calibration force }\left(i_{m 30}, i_{z 30}\right) \\
X_{N}= & \text { is the deflection corresponding to the maximum calibration force. }
\end{aligned}
$$

For easier explaining in this paper, the creep error calculated from maximum force is defined as shown in Eq. (2). And the creep recovery error that is calculated from measurement at zero force is defined as seen in Eq. (3):

$$
\begin{gathered}
C_{\text {max }}=\left|\frac{i_{m 300}-i_{m 30}}{X_{N}}\right| \times 100 \\
C_{\text {zero }}=\left|\frac{i_{z 300}-i_{z 30}}{X_{N}}\right| \times 100 .
\end{gathered}
$$

The relative reversibility error (hysteresis), $v$ was calculated from $v_{1}$ and $v_{2}$ as shown in Eqs. (4), (5) and (6):

$$
\begin{gathered}
v_{1}=\left|\frac{X_{4}^{\prime}-X_{3}}{X_{3}}\right| \times 100 \\
v_{2}=\left|\frac{X_{6}^{\prime}-X_{5}}{X_{5}}\right| \times 100 \\
v=\frac{v_{1}+v_{2}}{2} .
\end{gathered}
$$

The calculation uncertainty of creep was explained in ISO 376:2011 ${ }^{[1]}$ and EURAMET cg-4 version $2.0^{[3]}, w_{\text {creep }}$ is estimated as follow:

$$
w_{\text {creep }}=\frac{c}{\sqrt{3}}
$$

If the creep test is not measured, the uncertainty of creep can be estimated from reversibility error (hysteresis) as seen in Eq. (8):

$$
w_{\text {creep }}=\frac{v}{3 \sqrt{3}}
$$


Define $W C_{\max }$ as relative creep uncertainty calculated from $C_{\max }$.

Define $W C_{\text {zero }}$ as relative creep uncertainty calculated from $C_{\text {zero }}$.

Define $W v_{\text {max }}$ as relative creep uncertainty calculated from maximum reversibility error $\left(v_{\max }\right)$.

As known that creep behavior of material typically depends on type of material, loading pattern and time, the question is that which equation from Eq. (2) and Eq. (3) is the best for estimation of creep error. And the creep uncertainty should be calculated from creep measurement or from reversibility error. There are only few studies on the creep measurement of force proving instrument. Hasan et al. studied on the effect of loading schemes on creep and creep recovery for force measurement ${ }^{[4]}$. They found that creep effect was approximately $20 \%$ of the hysteresis value. Stenner studied on the comparison results between old and new version of ISO $376^{[5]}$. He found the differences could be more or less depended on type of transducer.

\section{Experimental Measurement Design}

In order to study creep and creep recovery of force proving instrument, the creep measurement data were collected from actual load cell's calibrations at NIMT in year 2012 and 2013. There are totally 98 calibration results of force proving instruments from various types and manufacturers. In this study, the NIMT's $100 \mathrm{kN}$ deadweight force standard machine was used as a standard to calibrate force proving instruments according to ISO $376: 2011^{[1]}$. These results were separated in 3 groups; 1) high precision load cell with AC bridge amplifier, 2) high precision load cell with DC bridge amplifier and 3) industrial type load cell and proving ring. Each of these groups was also separated to 2 types, which are compression and tension mode calibrations.

\subsection{Equipments}

Fig. 2 presents the deadweight force standard machine (DWM), which was used for calibration of force proving instruments. This machine had $100 \mathrm{kN}$ maximum capacity with 4 selectable calibration ranges as $10 \mathrm{kN}, 20 \mathrm{kN} 50 \mathrm{kN}$ and $100 \mathrm{kN}$. The relative uncertainty of DWM is $0.0035 \%{ }^{[6]}$.

The environment condition at NIMT's force laboratory was controlled at the temperature $23 \pm 1{ }^{\circ} \mathrm{C}$ and relative humidity is $55 \pm 15 \%$. 

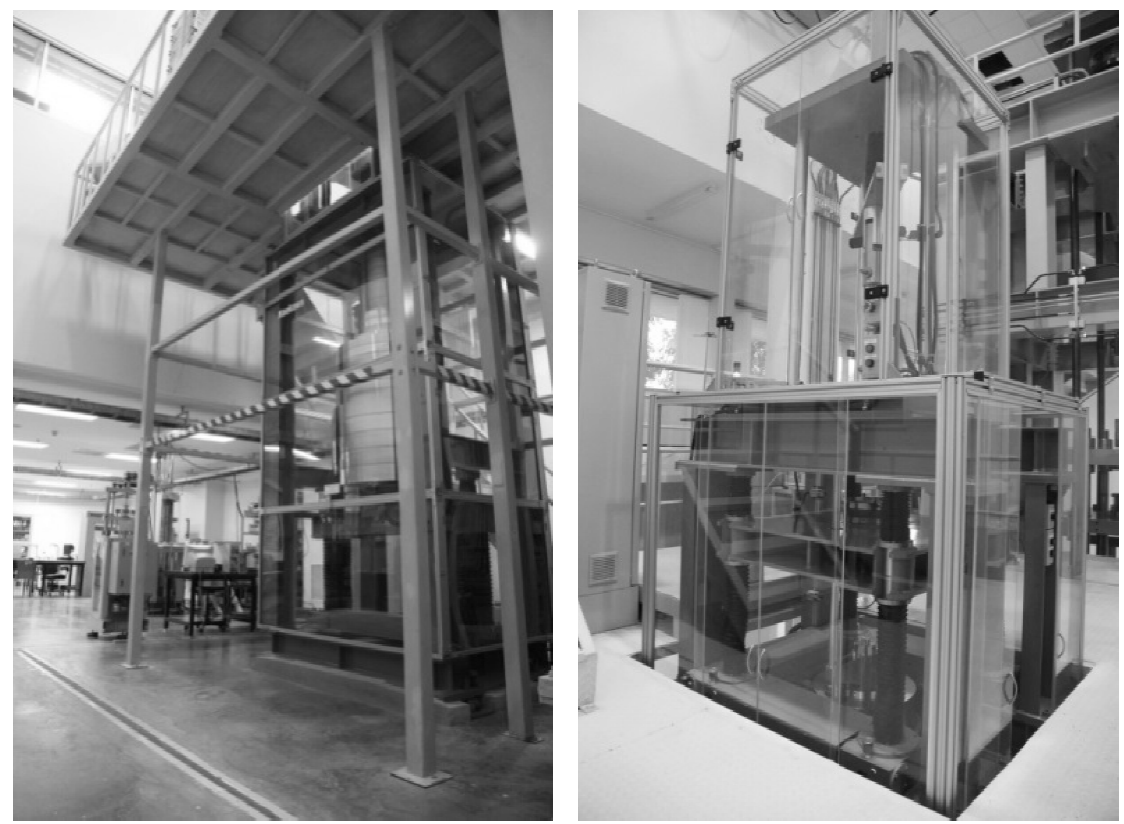

Fig.2 Deadweight force standard machine $100 \mathrm{kN}$ at NIMT.

\section{Result and Discussion}

The calibration results of force transducer are divided into 3 groups as follows.

\subsection{Precision load cell with AC bridge amplifier}

Table 1 shows the data from the equipment of precision force transducer carried out with precision digital measuring unit (AC bridge) for compression mode calibration. The table shows the calculation of relative creep uncertainty calculated from the creep measurement at maximum force $\left(W C_{\max }\right)$, creep recovery $\left(W C_{\text {zero }}\right)$ and the maximum value of relative reversibility error $\left(W v_{\max }\right)$. In order to compare in term of magnitude, $W C_{\max } / W v_{\max }$ and $W C_{\text {zero }} / W v_{\max }$ were calculated in the table. 
Table 1: Comparison of relative creep uncertainties for AC-bridge amplifier (compression mode).

\begin{tabular}{|c|c|c|c|c|c|}
\hline \multirow{2}{*}{ No. } & \multicolumn{3}{|c|}{ Relative creep uncertainty $\left(w_{\text {creep }}\right)$} & \multirow{2}{*}{$W C_{\max } / W v_{\max }$} & \multirow{2}{*}{$W C_{\text {zero }} / W v_{\max }$} \\
\hline & $W C_{\max }(\%)$ & $W C_{\text {zero }}(\%)$ & $W v_{\max }(\%)$ & & \\
\hline 1 & 0.0058 & 0.0046 & 0.0090 & 0.6417 & 0.5134 \\
\hline 2 & 0.0006 & 0.0003 & 0.0106 & 0.0544 & 0.0272 \\
\hline 3 & 0.0020 & 0.0003 & 0.0086 & 0.2331 & 0.0333 \\
\hline 4 & 0.0022 & 0.0012 & 0.0064 & 0.3403 & 0.1881 \\
\hline 5 & 0.0005 & 0.0002 & 0.0036 & 0.1298 & 0.0487 \\
\hline 6 & 0.0169 & 0.0019 & 0.0995 & 0.1697 & 0.0196 \\
\hline 7 & 0.0003 & 0.0009 & 0.0058 & 0.0500 & 0.1500 \\
\hline 8 & 0.0004 & 0.0001 & 0.0335 & 0.0129 & 0.0043 \\
\hline 9 & 0.0000 & 0.0035 & 0.0154 & 0.0000 & 0.2246 \\
\hline 10 & 0.0029 & 0.0017 & 0.0371 & 0.0780 & 0.0468 \\
\hline 11 & 0.0006 & 0.0012 & 0.0058 & 0.1000 & 0.2000 \\
\hline 12 & 0.0002 & 0.0002 & 0.0073 & 0.0316 & 0.0316 \\
\hline 13 & 0.0009 & 0.0002 & 0.0019 & 0.4689 & 0.0907 \\
\hline 14 & 0.0010 & 0.0000 & 0.0029 & 0.3528 & 0.0101 \\
\hline 15 & 0.0033 & 0.0030 & 0.0238 & 0.1366 & 0.1257 \\
\hline 16 & 0.0010 & 0.0001 & 0.0039 & 0.2591 & 0.0148 \\
\hline 17 & 0.0003 & 0.0003 & 0.0028 & 0.1138 & 0.0931 \\
\hline 18 & 0.0026 & 0.0014 & 0.0125 & 0.2076 & 0.1153 \\
\hline 19 & 0.0017 & 0.0006 & 0.0091 & 0.1893 & 0.0631 \\
\hline 20 & 0.0009 & 0.0012 & 0.0111 & 0.0782 & 0.1043 \\
\hline
\end{tabular}

The data from Table 1 was plotted as shown in Fig. 3(a). The x-axis represents the ratio between $W C_{\max }$ and $W v_{\max }$. The y-axis shows the ratio between $W C_{\text {zero }}$ and $W v_{\max }$. If the $\mathrm{x}$-axis of 0.33 indicating that the creep uncertainty calculated from reversibility error was about 3 times of the creep uncertainty calculated form creep measurement at max force. The graph also represents the ratio between $W C_{z e r o}$ and $C_{\text {max }}$. In case that an experiment data point is on the line $\mathrm{y}=0.5 \mathrm{x}$ (slope $=0.5$ ), the magnitude of $W C_{\max }$ will be 2 times of the $W C_{\text {zero. }}$. As seen in Fig. 3(a), from 20 experiments data, 16 of them have $W v_{\max }$ larger than 3 times of $W C_{\max }$ or $W C_{z e r o}$. In term of slope, there are 3 points of data in the region above the line $y=2 x$ and there are 8 points of data in the region below the line $y=0.5 x$. 
Fig. 3(b) shows data of precision load cell with AC type amplifier for tension mode. From 12 experiments data, 11 of them have $W v_{\max }$ larger than 3 times of $W C_{\max }$ or $W C_{\text {zero }}$. In term of slope, there are 7 points of data in the region below the line $\mathrm{y}=0.5 \mathrm{x}$.

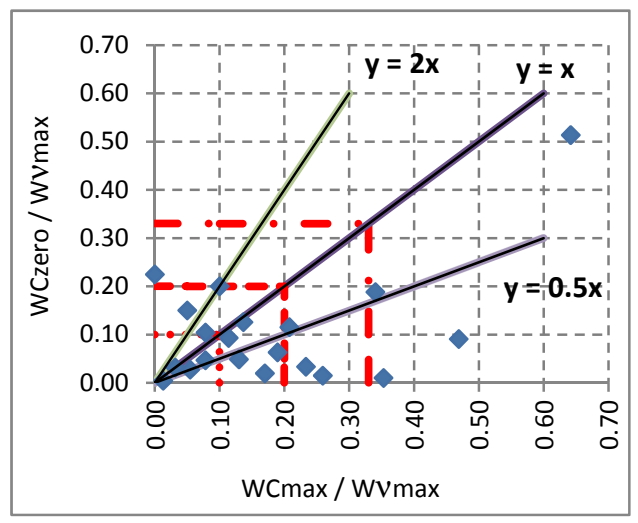

(a) Compression mode.

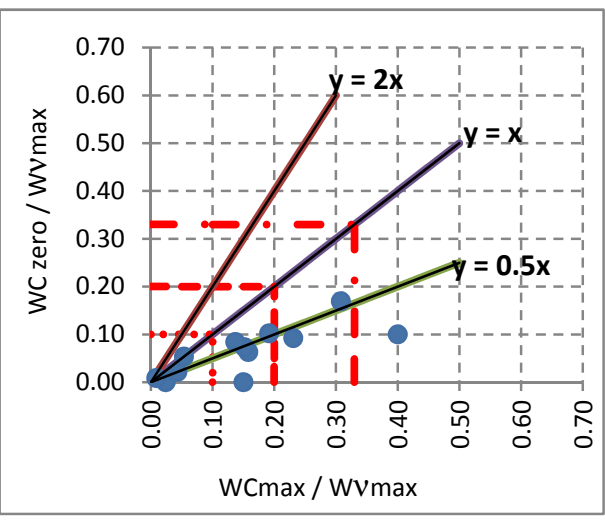

(b) Tension mode.

Fig.3 Relationship between creep uncertainties calculated from $C_{\max }, C_{\text {zero }}$ and $v_{\max }$ for precision load cell with AC bridge amplifier.

\subsection{Precision load cell with DC bridge amplifier}

Fig. 4 shows data of precision load cell with DC bridge amplifier in both compression and tension mode.

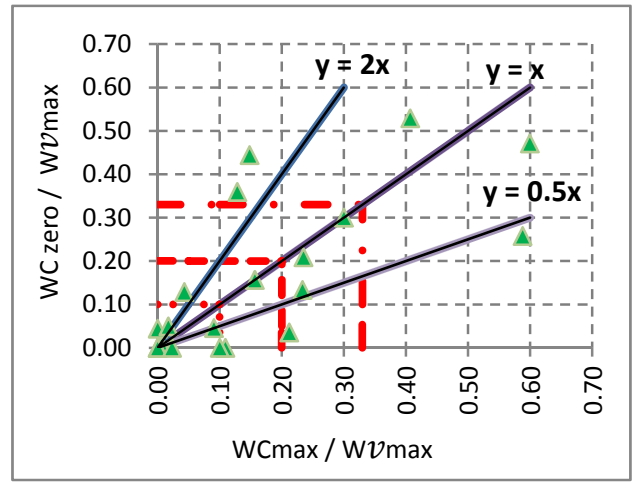

(a) Compression mode.

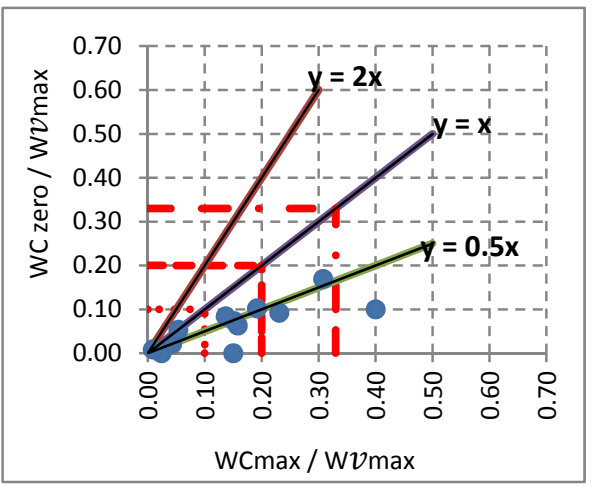

(b) Tension mode.

Fig.4 Relationship between creep uncertainties calculated from $\mathrm{C}_{\max }, \mathrm{C}_{\text {zero }}$ and $v_{\max }$ for precision load cell with DC bridge amplifier. 


\subsection{Industrial load cell DC bridge amplifier and proving ring}

Fig. 5 presents the calibration results from typical industrial load cell (IN) connected with the DC bridge amplifier. And also shows results of proving rings (PR) that the deflection were read from dial gauge or digital dial gauge.

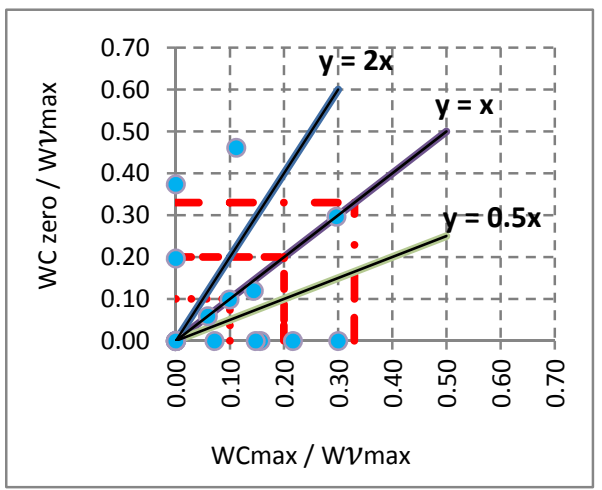

(a) Compression mode.

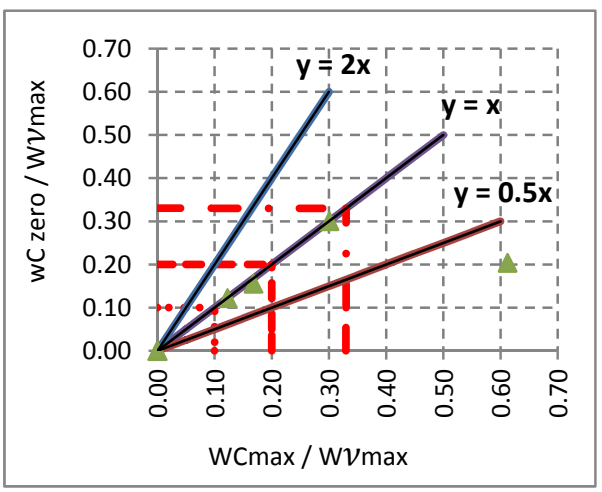

(b) Tension mode.

Fig.5 Relationship between creep uncertainties calculated from $\mathrm{C}_{\max }, \mathrm{C}_{\text {zero }}$ and $v_{\max }$ for industrial load cell and proving ring (IN \& PR).

\subsection{Summary of results}

To evaluate creep uncertainties calculated from 3 difference sources $\left(W C_{\text {max }}, W C_{\text {zero }}\right.$ and $W v_{\max }$ ), the results from Fig. 3, Fig. 4 and Fig. 5 were grouped with 2 criteria.

First, to compare agreement between $W C_{\max }$ and $W C_{\text {zero }}$, the results will agree with criteria $\mathrm{I}$ if the maximum between $\left(W C_{\max } / W C_{\text {zero }}\right)$ and $\left(W C_{\text {zero }} / W C_{\text {max }}\right)$ were less than or equal to 2 .

Second, to compare size of creep uncertainties calculated from creep measurement and reversibility error, the results will agree with criteria II if the maximum between $W C_{\text {max }}$ and $W C_{\text {zero }}$ divide by $W v_{\text {max }}$ were larger than or equal to $1 / 3$.

If the result agree with criteria I, it could be assumed that $W C_{\text {max }}$ close to $W C_{\text {zero }}$. In case of agreement with criteria II, it could be assumed that the difference of creep uncertainty calculated from creep measurement and from reversibility error were not significant. The grouping results were shown in Fig. 6. 


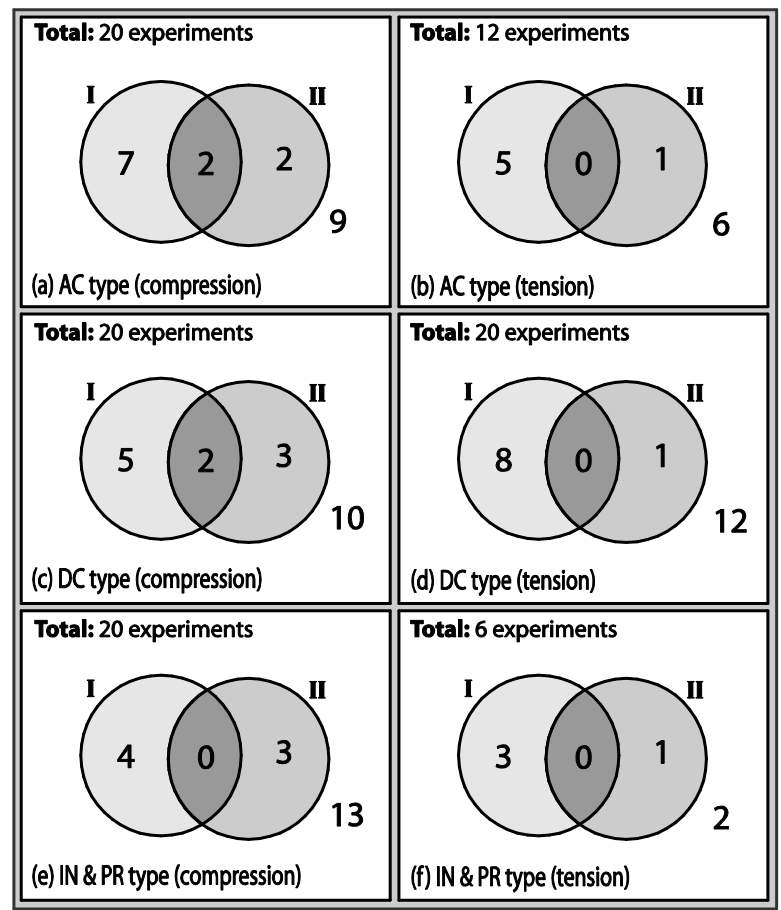

Fig.6 Grouping of experiments based on creep uncertainties calculated from difference sources according to ISO376:2011.

As seen in Fig. 6, from 98 experiments, 36 of them agree with criteria I. For criteria II, only 15 results agree. Moreover, only 4 results agree with both criteria. Indicating that, the creep uncertainties calculated from difference sources (according to ISO376:2011) could not be assumed equivalent. Based on the summary results, the creep properties should be represented by the maximum between $C_{\max }$ and $C_{\text {zero }}$. For unknown history of creep and reversibility characteristic of instruments, it should be more appropriate to estimate creep uncertainty from reversibility error.

\section{Conclusions}

1. Some of the results have zero values of either creep or creep recovery. Those zero values would possibly give some mistakes in uncertainty calculation.

2. More than $80 \%$ of experimental results reveal that the relative creep uncertainties estimated form reversibility error were more than 3 times of the relative creep uncertainties calculated from creep measurement.

3. There are only 4 from 98 of the experiments results of creep uncertainty (Fig. 6) agree both defined criteria. 
4. The values calculation from three sources of creep uncertainty are much different, thus those values could not be assumed equivalent to use.

5. From the experiment results, creep uncertainties calculated from reversibility were largest compare with the other sources. This give a conclusion that, for any load cell with unknown history of creep property, the reversibility error should be more appropriate to be use for calculation of creep uncertainty.

\section{Acknowledgment}

The authors are thankful to the National Institute of Metrology (Thailand) for the funding to perform this project.

\section{References}

1. ISO 376:2011, Metallic materials - Calibration of force-proving instruments used for the verification of uniaxial testing machines.

2. ISO 376:2004, Metallic materials - Calibration of force-proving instruments used for the verification of uniaxial testing machines.

3. Calibration Guide: Uncertainty of Force Measurements, $2^{\text {nd }}$ edn. (EURAMET cg-4. 03/2011).

4. E. Hasan, G. Haucke, R. Kumme, Effect of difference loading schemes on creep and creep recovery for force measurements, (Proceeding of the Joint international conference IMEKO TC3/TC5/TC22, Pattaya, Thailand, November 2010),p. 325-328.

5. L. Stenner, Comparison of the calibration results of industrial force transducers obtained based on the new vs. the old version of ISO 376, (Proceeding of the XX IMEKO World Congress, Busan, Republic of Korea, September 2012).

6. Kittipong Chaemthet, Chanchai Amornsakun, Noppadol Sumyong, Veera Tulasombut, Toshiyuki Hayashi, Kazunaga Ueda, A Bilateral Comparison of Force Standard between NIMT and NMIJ, (Proc. 6th Asia-Pacific Symposium on Measurement of Mass, Force, Torque and Density (APMF 2007), Sydney, Oct. 24-26, 2007), p.193-198. 